\title{
Diffusivity and solubility of oxygen in solid palladium
}

\author{
J. Gegner · G. Hörz · R. Kirchheim
}

Received: 8 May 2008/Accepted: 31 July 2008/Published online: 20 September 2008

(C) Springer Science+Business Media, LLC 2008

\begin{abstract}
The solid solubility $c_{\mathrm{O}}$ of oxygen in palladium in equilibrium with gaseous oxygen has been determined from absorption-desorption experiments for temperatures $T$ of 1123 and $1173 \mathrm{~K}$ and oxygen partial pressures $p_{\mathrm{O}_{2}}$ between $2.7 \times 10^{3}$ and $4.0 \times 10^{4} \mathrm{~Pa}$. The relationship between $c_{\mathrm{O}}, \quad p_{\mathrm{O}_{2}}$ and $T$ is given by $c_{\mathrm{O}}=a \sqrt{p_{\mathrm{O}_{2}}}$ $\exp \left(-\Delta H_{\mathrm{s}} / R T\right)$, where $R=8.314 \mathrm{JK}^{-1} \mathrm{~mol}^{-1}$ is the universal gas constant, $\Delta H_{\mathrm{s}}=-13.55 \mathrm{~kJ} / \mathrm{mol}$ denotes the heat of solution of oxygen in palladium and the constant $a$ amounts to $4.26 \times 10^{-5}$ at. $\% / \sqrt{\mathrm{Pa}}$ or $6.41 \times 10^{-8} \mathrm{wt} \% /$ $\sqrt{\mathrm{Pa}}$. The diffusion coefficient $D_{\mathrm{O}}$ of oxygen in solid palladium has been determined by incomplete isothermal internal oxidation of $\mathrm{Pd}-\mathrm{Fe}$ alloys using the data on the oxygen solubility in palladium. The temperature dependence of $D_{\mathrm{O}}$ obeys the Arrhenius equation $D_{\mathrm{O}}=D^{0}$ $\exp \left(-E_{\mathrm{d}} / R T\right)$ with pre-exponential factor $D^{0}=2.33 \times$ $10^{-7} \mathrm{~m}^{2} / \mathrm{s}$ and activation energy of diffusion of oxygen in palladium, $E_{\mathrm{d}}=102.76 \mathrm{~kJ} / \mathrm{mol}$
\end{abstract}

\footnotetext{
J. Gegner $(\bowtie)$

SKF GmbH, Abteilung Werkstoff-Physik, Ernst-Sachs-Strasse 5, 97424 Schweinfurt, Germany

e-mail: juergen.gegner@skf.com

J. Gegner

Institut für Werkstofftechnik, Universität Siegen,

Paul-Bonatz-Strasse 9-11, 57068 Siegen, Germany

G. Hörz

Max-Planck-Institut für Metallforschung, Seestrasse 92,

70174 Stuttgart, Germany

R. Kirchheim

Institut für Materialphysik, Georg-August-Universität Göttingen, Friedrich-Hund-Platz 1, 37077 Göttingen, Germany

e-mail: rkirch@ump.gwdg.de
}

\section{Introduction}

Palladium has found technical applications in a variety of fields due to some favourable properties. Of particular interest are the catalytic surface activity, the oxidation resistance under certain conditions of oxygen partial pressure and temperature, and the ability to provide a rapid and selective diffusion of hydrogen through the metal matrix. Considering the palladium-oxygen system, many investigations have been carried out dealing with the surface adsorption/desorption behaviour of oxygen at low temperatures. Information on the behaviour of oxygen in the bulk of palladium at high temperatures, however, is limited, in part questionable and/or contradictory [1-6].

In literature, only few studies are found that yield statements or data on the solid solubility of oxygen in palladium [1-4]. Early results stem from gravimetric investigations of the interaction of oxygen with palladium including the oxidation of the metal [1-3]. The reported rather high values of oxygen solubility were not confirmed by the measurements carried out later by Jehn and Grallath [4]. In their extensive study, palladium was exposed to oxygen and subsequently analysed. Extremely low oxygen solubility values were obtained by Park and Altstetter utilizing an electrochemical technique [5]. By using the same technique, measurements of the diffusivity of oxygen in palladium were carried out by the same authors [5]. However, like the solubility values the ones for the diffusion coefficients are very low and, therefore, are in conflict with the well-known kinetics of internal oxidation of palladium during annealing in oxygen or air [6-12]. This has also been shown in the previous work of the present authors [13], where rapid internal oxidation of $\mathrm{Pd}-\mathrm{Mg}$ alloys was observed and the resulting microstructures were analysed by using scanning electron microscopy [14, 15]. 
To further resolve the inconsistencies in the data of both solid solubility and the diffusivity of oxygen in palladium, we have carried out additional investigations. Our studies are based on the oxygen absorption and subsequent desorption of palladium and on the incomplete isothermal internal oxidation of $\mathrm{Pd}-\mathrm{Fe}$ alloys, respectively. In the present paper, the results are reported and discussed.

\section{Experimental}

Absorption and desorption experiments

The solid solubility of oxygen in palladium in equilibrium with gaseous oxygen was determined volumetrically in an ultrahigh vacuum (UHV) apparatus (base pressure $\left.10^{-6} \mathrm{~Pa}\right)$. The palladium samples used had a standard size of $6 \mathrm{~cm}$ in length, $0.8 \mathrm{~cm}$ in width and 100,130 or $150 \mu \mathrm{m}$ in thickness. They were prepared from palladium sheets (500 $\mu \mathrm{m}$ thick, purity $99.998 \mathrm{wt} \%$ ) by stepwise cold rolling and recrystallization annealing in argon. To reduce the possible effect of grain-boundary segregation of oxygen on the oxygen solubility, the conditions of this treatment were chosen such that a coarse-grained microstructure with an average grain size of about $130 \mu \mathrm{m}$ developed in the samples (details are given elsewhere [15]).

The palladium samples were exposed to pure oxygen (purity $99.997 \mathrm{vol} \%$ ) at pressures $p_{\mathrm{O}_{2}}$ ranging from $2.7 \times 10^{3}$ to $4.0 \times 10^{4} \mathrm{~Pa}$ and at temperatures $T$ of 1123 and $1173 \mathrm{~K}$. To avoid the formation of the surface oxide $\mathrm{PdO}$ during oxygen exposure, the pressure $p_{\mathrm{O}_{2}}$ at temperature $T$ was chosen to be lower than the dissociation pressure $p_{\mathrm{O}_{2}}^{\mathrm{d}}$ of PdO. The relationship between $p_{\mathrm{O}_{2}}^{\mathrm{d}}(\mathrm{PdO})$ and the reciprocal temperature $1 / T$ obeys the following relation according to literature data [16]

$p_{\mathrm{O}_{2}}^{\mathrm{d}}(\mathrm{PdO})=1.91 \times 10^{15} \exp \left(-\frac{27055}{T}\right) \mathrm{Pa}$.

Equation 1 shows that for a pressure $p_{\mathrm{O}_{2}}^{\mathrm{d}}$ of $4.0 \times 10^{4} \mathrm{~Pa}$, the condition $p_{\mathrm{O}_{2}}<p_{\mathrm{O}_{2}}^{\mathrm{d}}(\mathrm{PdO})$ is fulfilled at 1123 and $1173 \mathrm{~K}$, where $p_{\mathrm{O}_{2}}^{\mathrm{d}}(\mathrm{PdO})$ amounts to $6.6 \times 10^{4}$ and $1.8 \times 10^{5} \mathrm{~Pa}$, respectively. If, however, the palladium samples are cooled to room temperature in the oxygen gas atmosphere at $p_{\mathrm{O}_{2}}^{\mathrm{d}}=4.0 \times 10^{4} \mathrm{~Pa}$, the surface oxide $\mathrm{PdO}$ is formed at temperatures below $1100 \mathrm{~K}$, where $p_{\mathrm{O}_{2}}$ becomes larger than $p_{\mathrm{O}_{2}}^{\mathrm{d}}(\mathrm{PdO})$ (cf. Eq. 1). This situation will be discussed later.

It should be noted that the behaviour of palladium in an oxygen atmosphere principally might be influenced by the process of formation and evaporation of the volatile oxide $\mathrm{PdO}$. Since this reaction only occurs at temperatures much higher (above about $1273 \mathrm{~K}$ ) than the temperatures established in the present work [4], it is not considered further on.

To heat the samples to the desired absorption or desorption temperatures, a constant current was passed through them. To avoid a noticeable temperature gradient along the foils, palladium wires were spot-welded to the ends of the samples and connected to current clamps. The crosssection of these wires was determined by trial and error until at high temperatures a constant temperature within $\pm 10 \mathrm{~K}$ was established over the sample length.

For exposing the palladium foils to oxygen, the UHV vessel (that had been evacuated before to reach the base pressure of $10^{-6} \mathrm{~Pa}$ ) was separated from the pumping system and filled with oxygen until a definite constant pressure was established. Subsequently, the temperature of the sample was raised by resistance heating to the desired value. Equilibrium saturation of palladium with oxygen was achieved after annealing for about $1 \mathrm{~h}$ [15]. Then, the resistance heating was switched off and the temperature of the sample decreased below $473 \mathrm{~K}$ within a few seconds. This was checked occasionally by using a thin thermocouple, which was spot-welded to the palladium foil. After quenching the sample, the vessel was evacuated again until ultrahigh vacuum conditions were reached.

Prior to oxygen desorption of the $\mathrm{Pd}-\mathrm{O}$ solid solutions, the pumping speed $S$ of the UHV system was throttled to $S=1.48 \times 10^{-2} \mathrm{~m}^{3} / \mathrm{s}$ by choking the valve between the UHV vessel and the turbo-molecular pump. After that, a steady-state oxygen gas stream with a definite partial pressure of $p_{\mathrm{O}_{2}}^{\mathrm{d}} \approx 1 \times 10^{-5} \mathrm{~Pa}$ was established. The oxygen desorption of palladium saturated with dissolved oxygen was initiated by heating the samples rapidly to the desired temperature of 1123 or $1173 \mathrm{~K}$. The course of desorption was recorded by measuring the partial pressure $p(t)$ of oxygen in the vessel as a function of time $t$ using a mass spectrometer. By applying this dynamic method of desorption in an open system, the pressure $p(t)$ continually was lower than $10^{-2} \mathrm{~Pa}$, which is many orders of magnitude below the equilibrium oxygen pressure referring to the originally dissolved oxygen. Thus, the desorption reaction was not impeded by the oxygen present in the gas phase as long as $p(t)$ was markedly higher than the reference pressure $p_{\mathrm{O}_{2}}^{0}$. Moreover, the background reactions between residual carbon in the vessel and the released oxygen to form $\mathrm{CO}$ and $\mathrm{CO}_{2}$, which occur in vacuum systems on hot surfaces (e.g. on the wires of ionization gauges and on the sample itself), could be decisively suppressed. The amount $N_{\mathrm{O}_{2}}(t)$ of oxygen molecules released within the time $t$ was determined by numerical integration of the recorded pressure difference $\Delta p(t)=p(t)-p_{\mathrm{O}_{2}}^{0}$ with respect to the reference pressure $p_{\mathrm{O}_{2}}^{0} \approx 1 \times 10^{-5} \mathrm{~Pa}$ according to the following relation [15]: 
$N_{\mathrm{O}_{2}}(t)=\frac{V_{\mathrm{g}}}{k T_{\mathrm{g}}}\left[\Delta p(t)+\frac{S}{V_{\mathrm{g}}} \int_{0}^{t} \Delta p\left(t^{\prime}\right) \mathrm{d} t^{\prime}\right]$

Here, $V_{\mathrm{g}}=1.84 \times 10^{-2} \mathrm{~m}^{3}$ is the volume of the vacuum vessel, $S=1.48 \times 10^{-2} \mathrm{~m}^{3} / \mathrm{s}$ is the throttled pumping speed, $T_{\mathrm{g}}=295 \mathrm{~K}$ is the gas temperature, and $k$ is Boltzmann's constant. The integral in Eq. 2 was evaluated numerically by applying Newton-Cotes formulas [15].

The total amount $N_{\mathrm{O}_{2}}^{\text {tot }}$ of oxygen molecules released within the complete desorption period of about 35-40 $\mathrm{min}$ can be derived from Eq. 2 for $p(t)$ approaching the reference pressure $p_{\mathrm{O}_{2}}^{0}(t \rightarrow \infty \Rightarrow \Delta p \approx 0)$ :

$N_{\mathrm{O}_{2}}^{\mathrm{tot}}=\frac{S}{\mathrm{k} T_{\mathrm{g}}} \int_{0}^{\infty} \Delta p(t) d t$

The accuracy of the volumetric gas measuring system described above was estimated by calibrating. For this purpose, an additional small chamber was flanged to the UHV vessel. After the evacuation of the whole vacuum system, the small chamber (having a volume of $1.44 \times$ $10^{-3} \mathrm{~m}^{3}$ ) was separated from the UHV vessel by closing a valve between the chamber and the vessel and then was subsequently filled with oxygen under defined pressure. By adjusting the pumping speed $S$ and re-connecting the graduated chamber to the UHV vessel, the known amount of "released" oxygen molecules could be compared with the corresponding amount $N_{\mathrm{O}_{2}}^{\text {tot }}$ obtained according to Eq. 3 . By this procedure, the measuring accuracy was proved to be better than $20 \%$.

It should be emphasized that the quantity $N_{\mathrm{O}_{2}}^{\text {tot }}$, defined by Eqs. 2 and 3, principally includes the fraction of oxygen stemming from surface-adsorbed oxygen and surface oxide PdO. The latter had formed when the palladium samples, after exposure to oxygen at high temperatures, were cooled to room temperature in the oxygen gas atmosphere. As already described, this process occurred because during the sample cooling the oxygen gas pressure $p_{\mathrm{O}_{2}}$ became larger than the dissociation pressure $p_{\mathrm{O}_{2}}^{\mathrm{d}}(\mathrm{PdO})$ of the oxide PdO.

The formation of the surface oxide $\mathrm{PdO}$ could not be suppressed, not even by sample quenching within a few seconds. However, the oxygen bound in $\mathrm{PdO}$ could be removed easily by a short pre-heating of the samples in vacuum at about $873 \mathrm{~K}$, where the bulk oxygen was not yet mobile enough to leave the samples. This is demonstrated in Fig. 1, where the total amount $N_{\mathrm{O}_{2}}^{\text {tot }}$ of released oxygen molecules during desorption is plotted against temperature for a desorption treatment following absorption at $p_{\mathrm{O}_{2}}=$ $2.7 \times 10^{4} \mathrm{~Pa}$ and $1123 \mathrm{~K}$. The initial increase in $N_{\mathrm{O}_{2}}^{\text {tot }}$ at about $700 \mathrm{~K}$, which is followed by a plateau, can be attributed to the removal of adsorbed and oxidic bound surface oxygen. The drastic increase of $N_{\mathrm{O}_{2}}^{\text {tot }}$ at higher

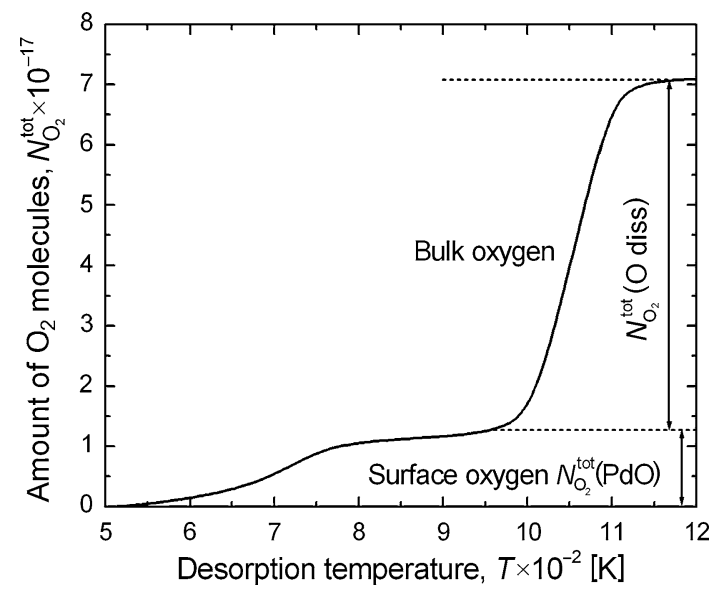

Fig. 1 Total amount $N_{\mathrm{O}_{2}}^{\text {tot }}$ of oxygen molecules released during desorption of a palladium foil (exposed to oxygen before at $p_{\mathrm{O}_{2}}=2.67 \times$ $10^{4} \mathrm{~Pa}$ and $1123 \mathrm{~K}$ ) as a function of the desorption temperature, $T$

temperatures above $1000 \mathrm{~K}$ corresponds to the oxygen dissolved in bulk palladium. From this part of $N_{\mathrm{O}_{2}}^{\text {tot }}$, i.e. $N_{\mathrm{O}_{2}}^{\text {tot }}-N_{\mathrm{O}_{2}}^{\text {tot }}(\mathrm{PdO})$, the solid solubility $c_{\mathrm{O}}\left(p_{\mathrm{O}_{2}}, T\right)$ of oxygen in palladium was determined. It must be noted that the residual amount of oxygen still dissolved in palladium when the final desorption pressure $p_{\mathrm{O}_{2}}^{0} \approx 10^{-5} \mathrm{~Pa}$ was reached is extremely low [4] and thus can be neglected.

For the oxygen desorption of palladium samples at 1123 or $1173 \mathrm{~K}$, respectively, the diffusion of oxygen in the palladium matrix to the surface was found to be the ratecontrolling reaction step [15]. Such a behaviour is typical, even for thin metal samples, in metal-gas systems exhibiting an endothermic (or weak exothermic) solution of the gas and rather low values of the diffusion coefficient of the gas in the solvent metal [17]. Examples are nitrogen desorption of molybdenum and tungsten [17]. Counter examples are nitrogen desorption of niobium and tantalum [17] and oxygen desorption of silver [15], where the desorption of thin metal samples is controlled by the recombination of dissolved gas atoms at the metal surface to form gas molecules. These metal-gas systems show a strong exothermic solution of gas in the solvent metal [17].

Considering now the present case of diffusion-controlled oxygen desorption of thin palladium foils, it was possible to derive the oxygen diffusivity $D_{\mathrm{O}}$ in palladium by measuring the reaction kinetics and comparing the experimental Eq. 2 with the corresponding theoretical relationship:

$$
\begin{aligned}
N_{\mathrm{O}_{2}}(t)= & \frac{1}{2} V_{\mathrm{s}}\left(c_{\mathrm{i}}-c_{\mathrm{f}}\right) \\
& \left\{1-\frac{8}{\pi^{2}} \sum_{n=1}^{\infty} \frac{1}{(2 n-1)^{2}} \exp \left[-(2 n-1)^{2} \pi^{2} \frac{D_{\mathrm{O}} t}{L^{2}}\right]\right\}
\end{aligned}
$$

Equation 4 is based on the solution of Fick's second law of diffusion in one preferred direction out of a thin plane 
sheet (foil thickness $L$ very small) assuming that in the range of small concentrations $c_{\mathrm{O}}$ of the dissolved oxygen, the diffusion coefficient $D_{\mathrm{O}}$ is independent of $c_{\mathrm{O}}[15,18$, 19]. $V_{\mathrm{s}}$ is the volume of the sample in $\mathrm{m}^{3} ; c_{\mathrm{i}}$ and $c_{\mathrm{f}}$ are, respectively, the oxygen concentrations in the palladium sample at the beginning (time $t=0$ ) and at the end $(t \rightarrow \infty)$ of desorption. These concentrations, expressed in oxygen atoms per unit volume, are given by the known solubilities $c_{\mathrm{O}}\left(p_{\mathrm{O}_{2}}, T\right)$ [4]. In Eq. 4, the factor $1 / 2$ takes into account the fact that during desorption, oxygen molecules are formed at the palladium surface by recombination of dissolved oxygen atoms. The described technique of determining diffusivities of gas atoms in metals by analysing the kinetics of desorption using expressions like that given in Eq. 4 could be considered an established method [18, 19].

Internal oxidation measurements

More extensive investigations on the diffusivity $D_{\mathrm{O}}$ of oxygen in palladium over a wide range of temperatures were based on the incomplete isothermal internal oxidation of dilute $\mathrm{Pd}-\mathrm{Fe}$ solid solutions containing 1 or 2 at.\% iron. The alloying of palladium (purity $99.998 \mathrm{wt} \%$ ) and iron (purity $99.99 \mathrm{wt} \%$ ) was carried out by arc melting and subsequent homogenization annealing of the ingots in argon. From these materials, by various procedures including cold deformation and annealing treatments, platelet-like samples (length about $1 \mathrm{~cm}$, thickness $400 \mu \mathrm{m}$ ) were obtained, which exhibited a fine- or a more coarse-grained microstructure (details are given in Ref. [15]).

The internal oxidation of the $\mathrm{Pd}-\mathrm{Fe}$ alloys was accomplished by annealing the samples in air (oxygen partial pressure $p_{\mathrm{O}_{2}}=2.1 \times 10^{4} \mathrm{~Pa}$ ) for various times at several temperatures between 1083 and $1573 \mathrm{~K}$. Under these conditions, the oxide $\mathrm{PdO}$ was not formed at the surface of the samples (cf. Eq. 1), whereas in the bulk of the material the iron oxide $\mathrm{Fe}_{2} \mathrm{O}_{3}$ was precipitated. This stoichiometry of the oxide was identified by the evaluation of selected area diffraction patterns recorded in a transmission electron microscope [15]. The oxide particles were large enough (about $1 \mu \mathrm{m}$ in diameter) to be visible in the scanning electron microscope (SEM). Thus, after the internal oxidation annealing and the subsequent quenching of the samples in water, the depth $\xi(t, T)$ of the $\mathrm{Fe}_{2} \mathrm{O}_{3}$ precipitation front in the palladium matrix could be determined from SEM cross-sectional micrographs.

The systematic measurements of the depth $\xi$ of the internally oxidized zones in $\mathrm{Pd}-\mathrm{Fe}$ alloys as a function of time for various temperatures allowed the determination of the diffusivity $D_{\mathrm{O}}$ of oxygen in palladium. In analysing our results, we followed the treatment of Wagner [20] describing the kinetics of internal oxide formation in the absence of an external oxide scale [6, 15, 20-25]. Under conditions where the internal oxidation is diffusion controlled, the depth $\xi$ of the internally oxidized zone should increase with oxidizing time $t$ at constant temperature $T$ and oxygen partial pressure $p_{\mathrm{O}_{2}}$ according to a parabolic law:

$\xi=2 \gamma \sqrt{D_{\mathrm{O}} t}$

$\gamma$ denotes a (time-independent) dimensionless parameter. Wagner showed that $\gamma$ can be evaluated for two limiting cases [20]. One of them corresponds to the situation observed in the present work. Here, during the internal oxidation of dilute solutions of iron in palladium, the outward diffusion of iron (diffusion constant $D_{\mathrm{Fe}}$ ) towards the oxidation front is very slow [26] in comparison to the inward diffusion of oxygen (diffusion coefficient $D_{\mathrm{O}}$ ). In addition, the concentration $c_{\mathrm{O}}$ of oxygen in equilibrium with the oxygen gas at the external surface of the alloy sample is much smaller than the concentration $c_{\mathrm{Fe}}$ of iron in the bulk alloy. Strictly speaking, $c_{\mathrm{O}}$ and $D_{\mathrm{O}}$ are, respectively, the solubility and diffusivity of oxygen in the internally oxidized edge zone material, but at the added iron contents of only 1 or 2 at.\% being mostly precipitated as an oxide, the difference from the corresponding data on pure palladium is negligible [27]. Extrapolating the values of $D_{\mathrm{Fe}}$ given in the literature 26 to higher and lower temperatures and using in advance our data on $D_{\mathrm{O}}$ (see Eq. 11 ), the ratio $D_{\mathrm{Fe}} / D_{\mathrm{O}}$ is found to range from $10^{-4}$ at $1573 \mathrm{~K}$ to $10^{-6}$ at $1083 \mathrm{~K}$. For these temperatures, the ratio $c_{\mathrm{O}} / c_{\mathrm{Fe}}$ amounts on the average to $10^{-2}$ [4]. Thus, the conditions $D_{\mathrm{Fe}} / D_{\mathrm{O}} \ll c_{\mathrm{O}} / c_{\mathrm{Fe}} \ll 1$ are fulfilled, which indicates that during the internal oxidation of dilute $\mathrm{Pd}-$ Fe alloys the movement of the precipitation front is essentially determined by the diffusion of oxygen in palladium [24]. Then, $\gamma$ is approximately equal to $\left[c_{\mathrm{O}} /\right.$ $\left.\left(2 v \cdot c_{\mathrm{Fe}}\right)\right]^{1 / 2}[20,22,24,25]$. Thus, Eq. 5 may be transformed to

$\xi^{2}=\frac{2}{v} \frac{c_{\mathrm{O}}}{c_{\mathrm{Fe}}} D_{\mathrm{O}} t \quad$ or $\quad c_{\mathrm{O}} D_{\mathrm{O}}=\frac{v}{2} c_{\mathrm{Fe}} \frac{\xi^{2}}{t}$,

where $c_{\mathrm{O}}$ is the equilibrium solubility of oxygen in palladium in an air of atmospheric pressure $\left(p_{\mathrm{O}_{2}}=2.1 \times\right.$ $10^{4} \mathrm{~Pa}$ ) at temperature $T . c_{\mathrm{Fe}}$ is the (initial) iron concentration in the bulk of the $\mathrm{Pd}-\mathrm{Fe}$ alloy and $v=3 / 2$ is the stoichiometric ratio $\mathrm{O} / \mathrm{Fe}$ in the precipitated iron oxide $\mathrm{Fe}_{2} \mathrm{O}_{3}$. Since in Eq. 6 the solubility $c_{\mathrm{O}}$ of oxygen in palladium is known from the literature [4] and the present work, the diffusivity $D_{\mathrm{O}}$ can be calculated from the product $c_{\mathrm{O}} D_{\mathrm{O}}$, which is designated as oxygen permeation constant [25]. 


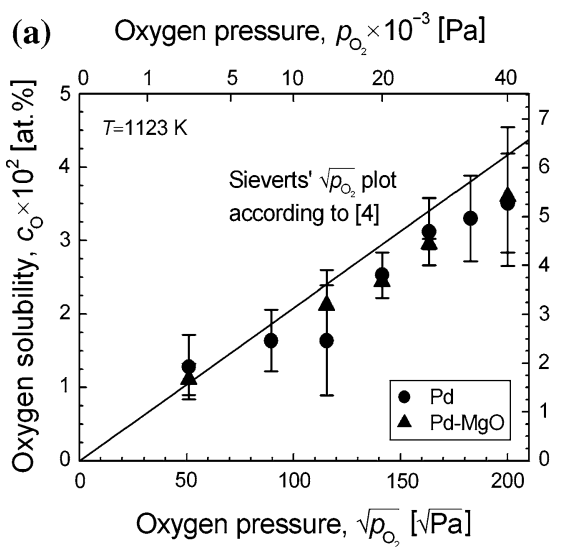

Fig. 2 Solid solubility $c_{\mathrm{O}}$ of oxygen in palladium vs. $\sqrt{p_{\mathrm{O}_{2}}}$ of the oxygen partial pressure. (a) Data for $1123 \mathrm{~K}$, shown separately as average values for palladium and $\mathrm{Pd}-\mathrm{MgO}$ samples and compared with the results according to Jehn and Grallath [4]. (b) Data for

\section{Results and discussion}

Solubility of oxygen in palladium

Figure $2 \mathrm{a}$ and $\mathrm{b}$ summarizes the results of the absorptiondesorption experiments on the solid solubility $c_{\mathrm{O}}\left(p_{\mathrm{O}_{2}}, T\right)$ of oxygen in the palladium matrix covering oxygen partial pressures $p_{\mathrm{O}_{2}}$ between $2.7 \times 10^{3}$ and $4.0 \times 10^{4} \mathrm{~Pa}$ and temperatures $T$ of 1123 and $1173 \mathrm{~K}$. The set of solubility data was enlarged by including corresponding results stemming from the absorption and desorption of $\mathrm{Pd}-\mathrm{MgO}$ foils. For preparing these samples, at first palladium was alloyed with magnesium (1.1 at.\% $\mathrm{Mg}$, purity of $\mathrm{Mg}$ : $99.99 \mathrm{wt} \%$ ) applying arc melting in argon. The ingots were shaped into foils by stepwise cold rolling and recrystallization annealing in argon. Samples of the dilute Pd1.1 at.\% $\mathrm{Mg}$ alloy exhibiting a similar coarse-grained microstructure and the same dimensions as those of palladium were completely internally oxidized in air at $1273 \mathrm{~K}$. This treatment led to the precipitation of numerous fine $\mathrm{MgO}$ particles (details are given in Refs. [14, 15]).

The $\mathrm{Pd}-\mathrm{MgO}$ foils were of special interest, because, due to the large total $\mathrm{Pd}-\mathrm{MgO}$ interface formed, it seemed possible to obtain information on the oxygen interfacial segregation from absorption-desorption experiments as described above for palladium. It was found, however, that at high temperatures of 1123 and $1173 \mathrm{~K}$, within the accuracy of measurements (below 20\%), oxygen segregation at the $\mathrm{Pd}-\mathrm{MgO}$ interfaces does not contribute to the total amount $N_{\mathrm{O}_{2}}^{\text {tot }}$ of oxygen released during desorption [13, 15]. It should be noted that due to the high affinity of oxygen to magnesium, dissociation of the $\mathrm{MgO}$ oxide during desorption is impossible, and thus, no additional oxygen stemming from the oxide particles can be released. The similar desorption behaviour of (b) Oxygen pressure, $p_{\mathrm{O}_{2}} \times 10^{-3}[\mathrm{~Pa}]$

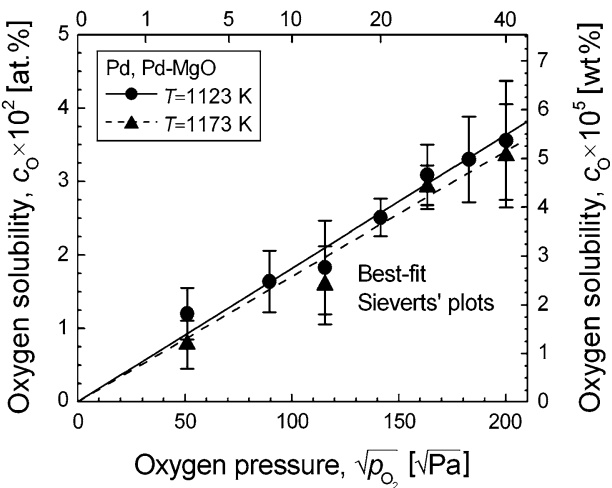

$1123 \mathrm{~K}$ and $1173 \mathrm{~K}$, shown as overall average values for both palladium and $\mathrm{Pd}-\mathrm{MgO}$ samples and fitted to the theoretically expected Sieverts' $\sqrt{p_{\mathrm{O}_{2}}}$-law (straight lines for $1123 \mathrm{~K}$ and $1173 \mathrm{~K}$ )

palladium and $\mathrm{Pd}-\mathrm{MgO}$ samples is reflected by the oxygen solubilities determined for the two groups of materials. In Fig. 2a, average values of $c_{\mathrm{O}}$ for each group of samples are plotted against the square root of the oxygen pressure, $\sqrt{p_{\mathrm{O}_{2}}}$, for a temperature of $1123 \mathrm{~K}$. Considering the scatter of data, it is found that no significant deviations between the data referring to palladium and $\mathrm{Pd}-\mathrm{MgO}$ samples exist and that our data are in rather good agreement with those reported by Jehn and Grallath [4] for palladium.

In Fig. 2b, the oxygen solubility $c_{\mathrm{O}}$ averaged with respect to both palladium and $\mathrm{Pd}-\mathrm{MgO}$ samples is plotted vs. $\sqrt{p_{\mathrm{O}_{2}}}$ for 1123 and $1173 \mathrm{~K}$. It can be seen that the equilibrium oxygen concentrations $c_{\mathrm{O}}$ are small and increase from about 0.01 at. $\%(0.15 \mathrm{wt} \mathrm{ppm})$ at $2.7 \times 10^{3} \mathrm{~Pa}$ to about 0.035 at. $\%(0.53 \mathrm{wt} \mathrm{ppm})$ at $4.0 \times 10^{4} \mathrm{~Pa}$, the temperature dependence being very weak. As demonstrated in Fig. 2b, the data can be fitted well by straight lines according to the expected validity of Sieverts' square root law, $c_{\mathrm{O}}$ $\left(c_{\mathrm{O}}\left(p_{\mathrm{O}_{2}}, T\right)=s(T) \sqrt{p_{\mathrm{O}_{2}}}\right)$ [4], which indicates that oxygen dissolves atomically in palladium.

Assuming that the parameter $s(T)$ depends exponentially on the reciprocal temperature [4], the oxygen solubility $c_{\mathrm{O}}$ in palladium can be described by the following Arrheniustype equation:

$c_{\mathrm{O}}\left(p_{\mathrm{O}_{2}}, T\right)=a \sqrt{p_{\mathrm{O}_{2}}} \exp \left(-\frac{\Delta H_{\mathrm{s}}}{R T}\right)$

Here, $R=8.314 \mathrm{JK}^{-1} \mathrm{~mol}^{-1}$ denotes the universal gas constant. The constant $a$ and the heat of solution $\Delta H_{\mathrm{s}}$ of oxygen in palladium were determined as follows:

$a=4.26 \times 10^{-5} \frac{\text { at. } \%}{\sqrt{\mathrm{Pa}}} \quad$ or $\quad a=6.41 \times 10^{-8} \frac{\mathrm{wt} \%}{\sqrt{\mathrm{Pa}}}$,

$\Delta H_{\mathrm{s}}=-13.55 \mathrm{~kJ} / \mathrm{mol}$ 
These results, based on only two temperatures, can be compared with the data derived from the previous work of Jehn and Grallath [4], which cover a broad range of temperatures between 1173 and $1573 \mathrm{~K}$ :

$a=3.16 \times 10^{-5} \frac{\text { at. } \%}{\sqrt{\mathrm{Pa}}} \quad$ or $\quad a=4.75 \times 10^{-8} \frac{\mathrm{wt} \%}{\sqrt{\mathrm{Pa}}}$,

$\Delta H_{\mathrm{s}}=-17.61 \mathrm{~kJ} / \mathrm{mol}$

Strikingly, the data according to Jehn and Grallath [4] are only moderately different from our results (cf. Fig. 2a). In particular, the heat of solution $\Delta H_{\mathrm{s}}$ of oxygen in palladium is also found to be slightly negative, showing that the reaction of oxygen dissolution in palladium is weakly exothermic. It should be noted, however, that our data and those of Jehn and Grallath [4] on the solubility of oxygen in palladium (in equilibrium with the oxygen gas atmosphere) are orders of magnitude higher than the terminal solubilities of oxygen in equilibrium with the palladium oxide $\mathrm{PdO}$ as reported by Park and Altstetter [5]. In this connection, it is worth noting that the diffusivities $D_{\mathrm{O}}$ of oxygen in palladium determined by Park and Altstetter [5] using the same electrochemical method are also extremely small (see next Section).

\section{Diffusivity of oxygen in palladium}

As an example for an internally oxidized Pd-Fe alloy with 2 at.\% Fe, Fig. 3 shows the SEM micrograph of the crosssection of a foil, which had been heated in air at $1273 \mathrm{~K}$ for $26 \mathrm{~h} 42 \mathrm{~min}$. The two oxidized regions, extending from the foil surface into the bulk of the material, contain numerous, homogeneously distributed fine $\mathrm{Fe}_{2} \mathrm{O}_{3}$ precipitates. The regions are separated from one another by a particle-free zone. From such micrographs, the depth $\xi(t, T)$ of internal oxidation was determined by measuring the average width of the central zone and considering the initial thickness of the foil [15]. Using these

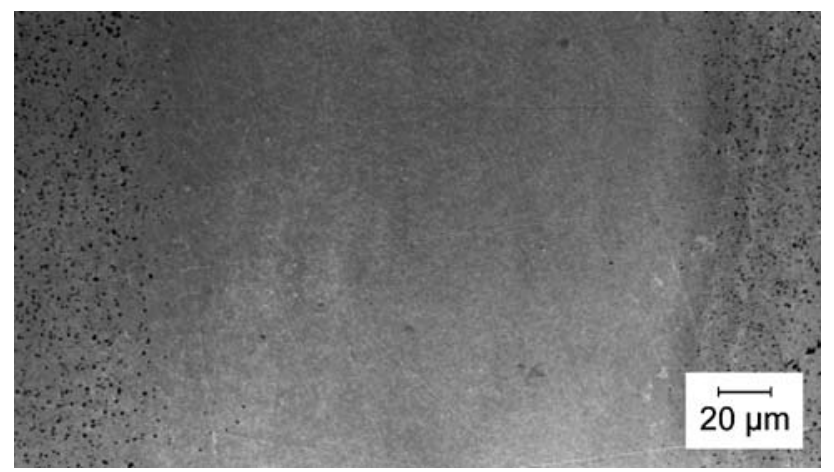

Fig. 3 SEM micrograph (secondary electron image) of the crosssection of a Pd-2 at.\% Fe sample after internal oxidation in air for $26 \mathrm{~h} 42 \mathrm{~min}$ at $1273 \mathrm{~K}$ $\xi(t, T)$ data, the products $c_{\mathrm{O}} D_{\mathrm{O}}$ for the solubility $c_{\mathrm{O}}$ and diffusivity $D_{\mathrm{O}}$ of oxygen in palladium have been calculated from Eq. 6.

It should be noted that the size of the $\mathrm{Fe}_{2} \mathrm{O}_{3}$ particles, which were precipitated during internal oxidation, increases with both annealing temperature and content of iron dissolved in palladium. Principally, the $\mathrm{Fe}_{2} \mathrm{O}_{3}$ particles formed along grain boundaries are much larger than those formed within the grains. Apart from heterogeneous nucleation, this might be due to both grain boundary segregation of iron in palladium and a higher mobility of iron along the grain boundaries. However, under the prevailing conditions, the grain boundaries obviously are not effective as preferred paths of oxygen penetration and oxidation of iron. Accordingly, relatively sharp boundaries of the oxidized zones were observed, like those shown in Fig. 3, for both the coarse-grained and the more fine-grained sample microstructures. Moreover, no significant differences in the depth $\xi(t, T)$ of internal oxidation were found for the two types of materials at given conditions of annealing time and temperature.

As shown in Fig. 4, for an oxygen pressure $p_{O_{2}}$ of $2.1 \times 10^{4} \mathrm{~Pa}$, the temperature dependence of the product $c_{\mathrm{O}} D_{\mathrm{O}}$, known as permeation constant $P_{\mathrm{O}}$, [25] can be described over the broad temperature range between 1083 and $1573 \mathrm{~K}$ by an Arrhenius-type equation as follows:

$$
\begin{aligned}
c_{\mathrm{O}} D_{\mathrm{O}} & =b \exp \left(-\frac{E_{\mathrm{p}}}{R T}\right) \\
& =1.07 \times 10^{-9} \exp \left(-\frac{10242}{T}\right) \text { at. } \% \mathrm{~m}^{2} / \mathrm{s}
\end{aligned}
$$

$E_{\mathrm{p}}=85.15 \mathrm{~kJ} / \mathrm{mol}$ is the apparent activation energy for oxygen permeation in palladium, for which the relation $E_{\mathrm{p}}=\Delta H_{\mathrm{s}}+E_{\mathrm{d}}$ is valid $\left(\Delta H_{\mathrm{s}}\right.$ and $E_{\mathrm{d}}$ are the heat of

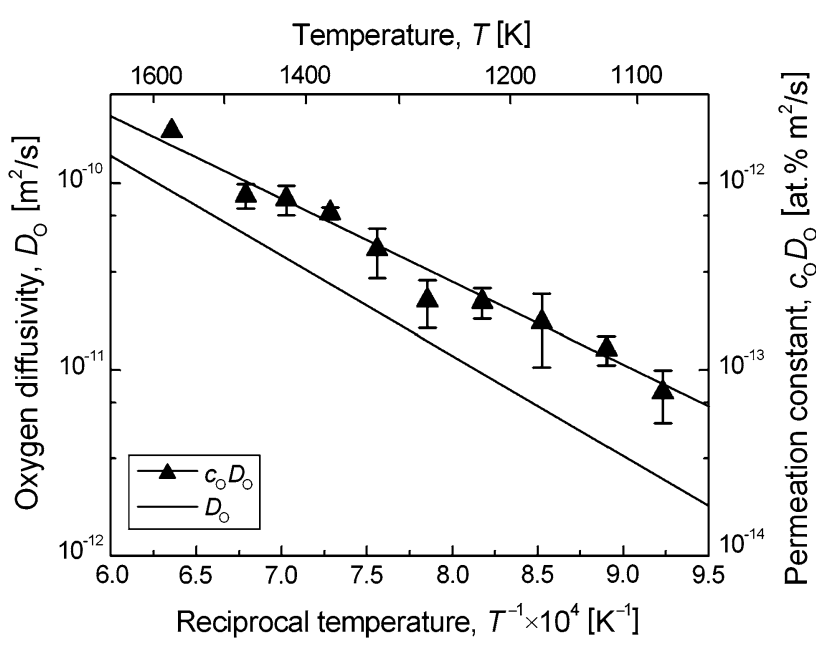

Fig. 4 Product $c_{\mathrm{O}} D_{\mathrm{O}}$ (permeation constant $P_{\mathrm{O}}$ ) for an oxygen partial pressure $p_{\mathrm{O}_{2}}$ of $2.1 \times 10^{4} \mathrm{~Pa}$ and diffusion coefficient $D_{\mathrm{O}}$ of oxygen in palladium vs. reciprocal temperature $1 / T$ 
solution and the activation energy for diffusion of oxygen, respectively).

With the oxygen solubilities $c_{\mathrm{O}}$ given in the work of Jehn and Grallath [4] for $2.1 \times 10^{4} \mathrm{~Pa}$ and extrapolated from the temperature range $1173 \mathrm{~K}<T<1573 \mathrm{~K}$ to lower temperatures $(1083 \mathrm{~K})$, the diffusion coefficient $D_{\mathrm{O}}$ of oxygen in palladium was determined and found to obey the following Arrhenius equation (cf. Fig. 4):

$$
\begin{aligned}
D_{\mathrm{O}} & =D^{0} \exp \left(-\frac{E_{\mathrm{d}}}{R T}\right) \\
& =2.33 \times 10^{-7} \exp \left(-\frac{12400}{T}\right) \mathrm{m}^{2} / \mathrm{s},
\end{aligned}
$$

where $R=8.314 \mathrm{JK}^{-1} \mathrm{~mol}^{-1}$ denotes the universal gas constant and $E_{\mathrm{d}}=102.76 \mathrm{~kJ} / \mathrm{mol}$ is the activation energy for the oxygen diffusion in the palladium matrix.

The results on the diffusivity $D_{\mathrm{O}}(T)$, summarized in Eq. 11 and Fig. 4, are supported by the investigation of the kinetics of the diffusion-controlled oxygen desorption of thin palladium samples at 1123 and $1173 \mathrm{~K}$. This is illustrated in Fig. 5 for the desorption of a $100-\mu \mathrm{m}$-thick palladium foil at $1123 \mathrm{~K}$. Here, the measured and the theoretical $N_{O_{2}}(t)$ curves of the amount of released oxygen as a function of annealing time as given by Eqs. 2 and 4, respectively, are shown. The best fit of the theoretical with the experimental curve was achieved by computer simulation using the diffusion coefficient $D_{\mathrm{O}}$ of oxygen in palladium as a fitting parameter in Eq. 4 yielding $D_{\mathrm{O}}=3.5 \times 10^{-12} \mathrm{~m}^{2} / \mathrm{s}$. This value is similar to that predicted by Eq. 11 for $1123 \mathrm{~K}, D_{\mathrm{O}}=3.9 \times 10^{-12} \mathrm{~m}^{2} / \mathrm{s}(\mathrm{cf}$. Fig. 5).

The diffusivity data of the present work given in Eq. 11 can be compared to those reported by Park and Altstetter

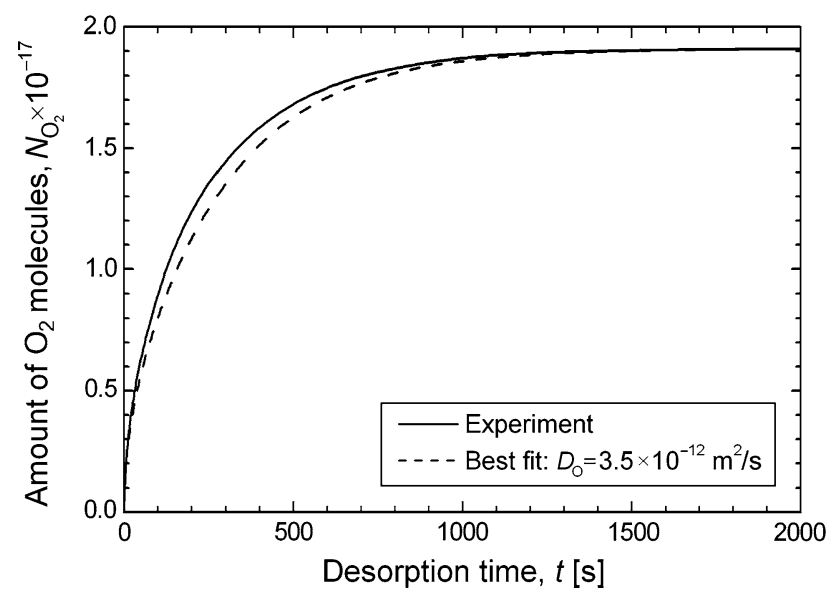

Fig. 5 Isothermal oxygen desorption of a $100-\mu \mathrm{m}$-thick palladium foil at $1123 \mathrm{~K}$ (exposed to oxygen before at $p_{\mathrm{O}_{2}}=2.67 \times 10^{3} \mathrm{~Pa}$ and $1123 \mathrm{~K})$. Time dependence of the amount $N_{\mathrm{O}_{2}}(t)$ of released oxygen, as determined experimentally and calculated theoretically according to Eq. 4
[5] for temperatures between 1173 and $1473 \mathrm{~K}$. There is an astonishingly good agreement between the activation energies $E_{\mathrm{d}}$ for oxygen diffusion in palladium amounting to $98 \mathrm{~kJ} / \mathrm{mol}$ (work of Park and Altstetter [5]) and $103 \mathrm{~kJ} / \mathrm{mol}$ (this work). However, according to the measurements presented above, the pre-exponential factor $D^{0}$ in Eq. 11 is equal to $2.33 \times 10^{-7} \mathrm{~m}^{2} / \mathrm{s}$, whereas in the paper of Park and Altstetter [5], $D^{0}$ is reported to be smaller by two orders of magnitude $\left(D^{0}=1.03 \times 10^{-9} \mathrm{~m}^{2} / \mathrm{s}\right)$. Interestingly, also the terminal solubilities $c_{\mathrm{O}}$ of oxygen in palladium in equilibrium with the oxide $\mathrm{PdO}$, measured by the same authors [5] and using the same electrochemical method, are much lower than the present data and those of Jehn and Grallath [4] on the solubility $c_{\mathrm{O}}$ of oxygen in palladium.

Moreover, the diffusion coefficient $D_{\mathrm{O}}$ of oxygen in palladium given in the present work agrees quite well with the data obtained by Gegner [6] from incomplete nonisothermal internal oxidation of a Pd-9 at.\% Fe alloy in air. Here, a stronger temperature dependence of $D_{\mathrm{O}}$ was found between 1073 and $1473 \mathrm{~K}$. The pre-exponential factor $D^{0}$ and the activation energy $E_{\mathrm{d}}$ of diffusion of oxygen in palladium were reported to be $5.32 \times 10^{-5} \mathrm{~m}^{2} / \mathrm{s}$ and $155.71 \mathrm{~kJ} / \mathrm{mol}$, respectively [6].

Contrary to the low values of $D_{\mathrm{O}}$ and $c_{\mathrm{O}}$ reported by Park and Altstetter [5], the internal oxidation of palladium base alloys is easily possible [6-12, 14, 16]. Using the higher values of $D_{\mathrm{O}}$ and $c_{\mathrm{O}}$ given in the present work and by Jehn and Grallath [4], the reaction times for the complete internal oxidation of Pd-1.1 at.\% $\mathrm{Mg}$ alloys in air could be estimated, and a good agreement with the experimental observations was obtained [13-15].

\section{Conclusions}

The solid solubility $c_{\mathrm{O}}$ of oxygen in palladium in equilibrium with gaseous oxygen at 1123 and $1173 \mathrm{~K}$ was determined volumetrically by means of absorptiondesorption experiments and found to be very low. For oxygen partial pressures $p_{\mathrm{O}_{2}}$ between $2.7 \times 10^{3}$ and $4.0 \times 10^{4} \mathrm{~Pa}$, the oxygen equilibrium concentrations $c_{\mathrm{O}}$ range from 0.01 at. $\%(0.15 \mathrm{wt} \mathrm{ppm})$ to 0.035 at. $\%$ (0.53 wt ppm). At constant temperature, the oxygen solubility $c_{\mathrm{O}}$ is proportional to $\sqrt{p_{\mathrm{O}_{2}}}$, i.e. Sieverts' law is valid, indicating that oxygen dissolves atomically in palladium.

The temperature dependence of $c_{\mathrm{O}}$ is weak. Assuming an Arrhenius-type relation, $c_{O}=a \sqrt{{\mathrm{O}_{2}}_{2}} \exp \left(-\Delta H_{\mathrm{s}} / R T\right)$, where $a=4.26 \times 10^{-5}$ at. $\% / \sqrt{\mathrm{Pa}}$ or $a=6.41 \times$ $10^{-8} \mathrm{wt} \% / \sqrt{\mathrm{Pa}}$ and $R=8.314 \mathrm{JK}^{-1} \mathrm{~mol}^{-1}$ (universal gas constant), the heat of solution $\Delta H_{\mathrm{s}}$ of oxygen in palladium is slightly negative, $\Delta H_{\mathrm{s}}=-13.55 \mathrm{~kJ} / \mathrm{mol}$. Thus, the solution of oxygen in palladium is an exothermic reaction. 
The data on the solubility $c_{\mathrm{O}}$ of oxygen in palladium obtained in this work confirm the previous results reported by Jehn and Grallath [4] for a wider range of temperatures. The knowledge of this data was necessary for the determination of the diffusion coefficient $D_{\mathrm{O}}$ of oxygen in palladium from the investigation of the kinetics of the incomplete isothermal internal oxidation of Pd-Fe alloys with 1 or 2 at.\% $\mathrm{Fe}$, which yields the permeation constant $P_{\mathrm{O}}=c_{\mathrm{O}} D_{\mathrm{O}}$. For temperatures between 1083 and $1573 \mathrm{~K}$, the temperature dependence of the diffusivity $D_{\mathrm{O}}$ can be described by the Arrhenius equation $D_{\mathrm{O}}=D^{0} \exp \left(-E_{\mathrm{d}} /\right.$ $R T$ ), where $D^{0}=2.33 \times 10^{-7} \mathrm{~m}^{2} / \mathrm{s}$ is the pre-exponential factor, $R=8.314 \mathrm{JK}^{-1} \mathrm{~mol}^{-1}$ is the universal gas constant, and $E_{\mathrm{d}}=102.76 \mathrm{~kJ} / \mathrm{mol}$ is the activation energy for oxygen diffusion in palladium. The data on the diffusion coefficient $D_{\mathrm{O}}$ were confirmed by measuring and analysing the diffusion-controlled oxygen desorption of thin palladium foils.

A comparison of the presented results with literature data was given and discussed. The data reported in this work are in agreement with the observation that a series of palladium base alloys exhibit fast internal oxidation and were proved to be reliable by the experimentally observed annealing times for the complete internal oxidation of Pd-Mg alloys.

In future work, this diffusivity data (extrapolated to lower temperatures) may serve as the basis for modelling the overall kinetics of oxygen segregation at internal Pd-oxide interfaces including oxygen diffusion. For this purpose, analytic solutions of Fick's second law, which are restricted to special cases or simplifying assumptions [28], shall be extended by numerical simulations based on the finite difference or finite element method.

\section{References}

1. Raub E, Plate W (1957) Z Metallk 48:529

2. Krier CA, Jaffee RI (1963) J Less Common Met 5:411. doi: 10.1016/0022-5088(63)90055-9
3. Campbell CT, Foyt DC, White JM (1977) J Phys Chem 81:491. doi: $10.1021 / \mathrm{j} 100520 \mathrm{a} 024$

4. Jehn H, Grallath E (1984) In: Kudryk V, Corrigan DA, Liang WW (eds) Precious metals: mining, extraction, and processing. TMS-AIME, Warrendale, pp 595-602

5. Park JW, Altstetter C (1985) Scr Metall 19:1481. doi:10.1016/ 0036-9748(85)90155-3

6. Gegner J (2006) In: Proceedings of the 2006 international conference on mathematical modeling and computer simulation of material technologies, vol 1, MMT-2006, Materials Research Center (College of Judea and Samaria, Ariel, Israel), chap 3, pp 36-45

7. Thomas DE (1951) Trans AIME 191:926

8. Chaston JC (1965) Platin Met Rev 9:126

9. Huang XY, Mader W, Eastman JA, Kirchheim R (1988) Scr Metall 22:1109. doi:10.1016/S0036-9748(88)80113-3

10. Huang XY, Mader W, Kirchheim R (1991) Acta Metall Mater 39:893. doi:10.1016/0956-7151(91)90289-D

11. Muschik T, Rühle M (1992) Philos Mag A 65:363. doi: $10.1080 / 01418619208201528$

12. Groen HB, De Hosson JTM (1998) Scr Mater 38:769. doi: 10.1016/S1359-6462(97)00547-2

13. Gegner J, Hörz G, Kirchheim R (1997) Interface Sci 5:231. doi: 10.1023/A:1008611820425

14. Gegner J, Weible A (2000) Z Metallk 91:1026

15. Gegner J (1995) Ph.D. thesis, University of Stuttgart

16. Jehn H, Speck H, Hehn W, Fromm E, Hörz G (1982) In: Behrens $\mathrm{H}$, Ebel G (eds) Gases and carbon in metals, Pt. XIX, platinum metals (1), palladium, in physics data, (Fachinformationszentrum Energie, Physik, Mathematik, Karlsruhe), No. 5-19, p 14

17. Hörz G (1976) In: Fromm E, Gebhardt E (eds) Gase und Kohlenstoff in Metallen. Springer, Berlin, pp 147-160

18. Shewmon P (1989) Diffusion in solids, 2nd edn. TMS, Warrendale, $p 26$

19. Crank J (1990) The mathematics of diffusion, 2nd edn. Clarendon, Oxford

20. Wagner C (1959) Z Elektrochem 63:772

21. Maak F (1961) Z Metallk 52:545

22. Verfurth JE, Rapp RA (1964) Trans AIME 230:1310

23. Bohnenkamp K, Engell HJ (1964) Arch Eisenhuttenwes 35:1011

24. Rapp RA (1965) Corrosion 21:382

25. Iden DJ, Himmel L (1969) Acta Metall 17:1483. doi:10.1016/ 0001-6160(69)90012-1

26. Fillon J, Calais D (1977) J Phys Chem Solids 38:81. doi: 10.1016/0022-3697(77)90150-0

27. Meijering JL (1971) In: Herman H (ed) Advances in Materials Research, vol 5. Wiley-Interscience, Chichester, pp 1-81

28. Gegner J (2002) Proceedings of the 2001 materials week [CDROM, ISBN 3-88355-302-6], Werkstoffwoche-Partnerschaft 